\title{
NOTICIAS DESDE ESPAÑA VISTAS DESDE ITALIA
}

\author{
Valerio Paolo Mosco
}

Los viajes de ida y vuelta que se han sucedido a lo largo de la historia entre la arquitectura italiana y española han dado lugar a una prolífica correspondencia, materializada en un destacado catálogo de obras y textos. Una mirada desde Italia a la segunda mitad del siglo XX de esta consolidada relación permite destacar una serie de protagonistas cuyas aportaciones han ido determinando, década a década, capítulos claves que nos ayudan a comprender el momento de intenso diálogo que hoy en día podemos apreciar en la arquitectura contemporánea de ambos países.

Palabras clave: Italia, España, tradición, Rafael Moneo, Aldo Rossi Keywords: Italy, Spain, tradition, Rafael Moneo, Aldo Rossi

La deuda que mantiene la arquitectura española con la ital iana ha sido frecuentemente objeto de discusión. Desde los años cincuenta hasta los ochenta, varias generaciones de arquitectos españoles se formaron gracias al estudio de proyectos de arquitectos como L uigi M oretti, I gnazio Gardella, Franco A lbini o A Ido Rossi y a la lectura de Zevi y Tafuri, así como de las revistas C asabella, D omus o Lotus. Sobre este hecho han insistido O riol B ohigas y en especial Rafael M oneo: "R ecuerdo que los libros italianos eran nuestra puerta de entrada a la arquitectura moderna. M e siento obligado a mencionar, dada la enorme influencia que ejercían sobre nosotros, los textos de Bruno Zevi y Giulio Carlo A rgan, que leíamos en traducciones argentinas. Zevi nos hacía soñar con una arquitectura que al canzaba la plenitud de la obra de Frank L loyd W right, mientras que A rgan nos hacía soñar con la tierra prometida de las vanguardias. El panorama que describían los críticos italianos nos transportaba a un mundo más allá de nuestros límites, y nos proporcionaba una visión de la arquitectura absolutamente distinta a la que teníamos en nuestro país que, dada la situación, podría haberse considerado insular" ${ }^{1}$. Vale la pena que nos detengamos sobre estas palabras de M oneo. Tras la Segunda Guerra M undial, la arquitectura italiana, como en un intento de distanciarse del régimen fascista, se adentró por un tiempo en un eclecticismo que manipulaba el lenguaje del movimiento moderno, en ocasiones con cierta audacia. Esta manipulación produjo algunas obras sincréticas, elitistas y populares, rigurosas y excéntricas al mismo tiempo, que consciente o inconscientemente intentaban firmar la paz con la historia, un intento que caracterizó al periodo posmoderno. E ra un eclecticismo y un sincretismo típico de un país "recién llegado", que se adentraba tarde en la modernidad y que, por ese motivo, organizó sus propios recursos de manera heterodoxa mediante la experimentación de nuevas formas de expresión, que dieron como resultado notables fracturas de los cánones de la modernidad más avanzada. En realidad, fue precisamente este eclecticismo sincrético, contradictorio pero fértil, el que sedujo a los arquitectos españoles de la generación de M oneo y de la anterior, que lo percibían como una alternativa a la ortodoxia moderna que hasta poco antes, con el GATEPAC y J osep L Iuís Sert, había copado la arquitectura española. Es decir, esa renovada relación con la historia de la que hacían gala los italianos atrajo a los españoles durante aquellos años. R especto a esto, M oneo apunta que "la ambición por utilizar la historia como cimiento para conocer la arquitectura supuso para mí una revelación. Fueron tiempos interesantes para los estudios sobre historia de la arquitectura... una arquitectura consciente de cómo había evolucionado y que, en consecuencia, era respetuosa con el pasado, por lo que se convirtió en una alternativa metodológica al rigorismo purista del movimiento moderno" 2 . A sí que la historia se convirtió en un método, en un antídoto contra el profesionalismo superficial y en un instrumento para unificar el planeamiento urbano y la arquitectura, un mensaje que llegaba desde I talia por múl tiples caminos y con múltiples implicaciones: por una parte, la historia de B runo Zevi, práctica, adaptable a la época contemporánea y nada autocomplaciente; por la otra, la historia de M anfredo Tafuri, filológica y centrada en reconstruir las condiciones en que se concebían y ejecutaban las obras.
1. MONEO, Rafael, "L'architettura italiana attuale vista dalla Spagna", en L'altra modernità. Considerazioni sul futuro dell'architettura, DÍEZ MEDINA, Carmen y PIERINI, Simona (eds.), 2012, Milán: Christian Marinotti, p. 105. Respecto a este tema, véase también BAGNATO, Vincenzo Paolo, "MBM Arquitectes. Intervista a Oriol Bohigas", en D'Architettura, núm. 28 (2005), pp. 176-183. Respecto a la relación entre las arquitectura española e italiana durante los últimos años, véase ARGENTI, Maria and TOPPETTI, Fabrizio, "Architetture Iberiche", en Rassegna di architettura e urbanistica, n. 147 (2015).

2. Ibid., p. 109. 
Fig. 1. Eclecticismo español e italiano. Analogías: Paolo Portoghesi, proyecto de torre en Santa Marinella, 1964; Manue Fisac, “La Pagoda”, 1965-1970.

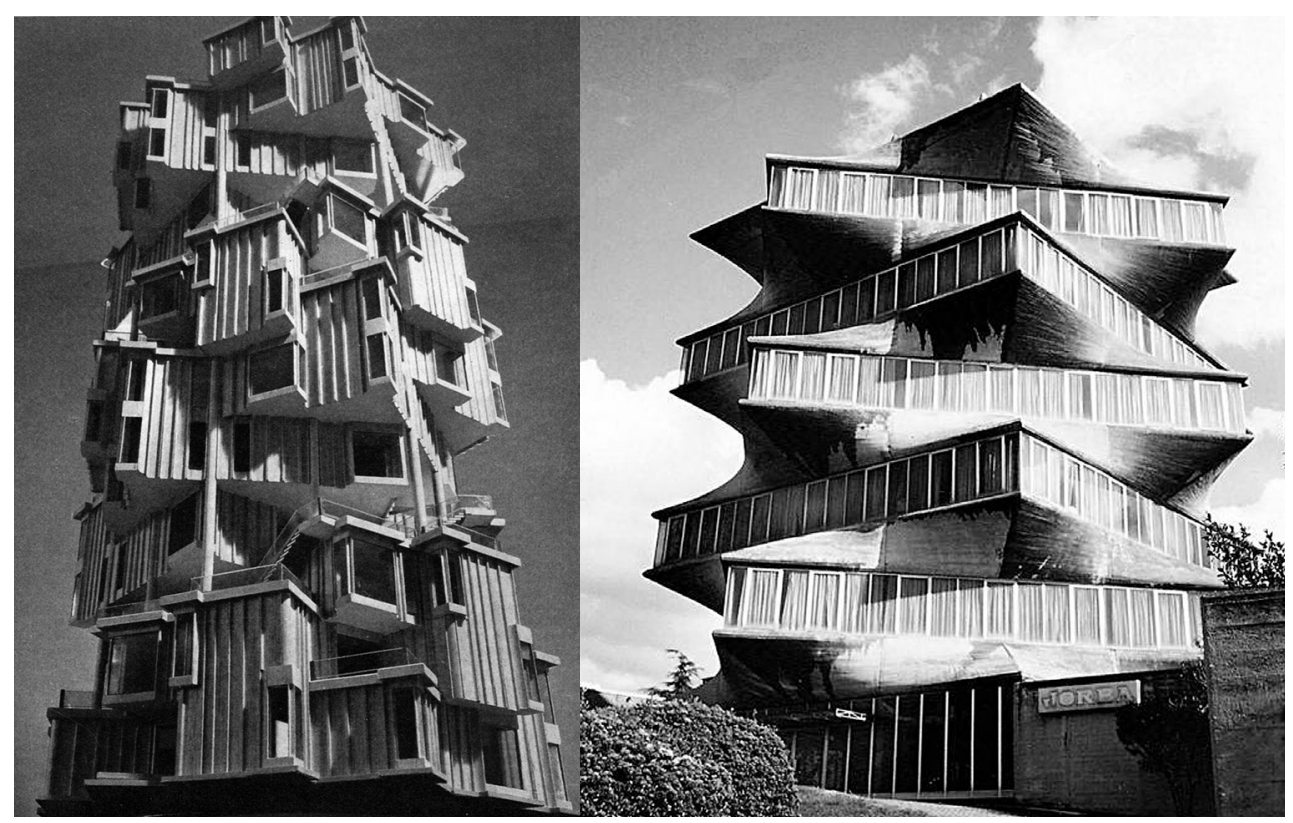

Lo que podría definirse como la separación de Italia, 0 al menos como una reducción de la dependencia española de Italia, comenzó durante los primeros años setenta. A partir de 1969, la situación política y social italiana fue empeorando: el radicalismo que a finales de los sesenta había sido la expresión de un deseo de dar voz a las necesidades de una sociedad irreconocible empezó a derivar en disputas partidistas que se proponían derrocar los equilibrios políticos de la posguerra. Como resultado, la imagen de Italia que se percibía desde España cambió completamente. M oneo escribe: "Italia dejó de ser ese paraíso fascinante y se convirtió en un verdadero campo de batalla ideológico". Pier Vittorio A ureli, rememorando aquellos años, apuntó que las expresiones de más éxito de la arquitectura italiana de esa época, los radicales Superstudio y A rchizoom, y la Tendenza de Giorgio Grassi y A Ido Rossi, eran dos alternativas de la diáspora de la izquierda italiana durante aquellos años en que, tras conquistar la hegemonía de la cultura nacional, se había dividido entre el laborismo y el sindical ismo por una parte, y por otra la ortodoxia aún vinculada con el Partido Comunista ${ }^{3}$. El elemento aglutinador era la convicción de que la arquitectura sería testigo de ese compromiso de derrocar el sistema y que enviaría un mensaje en contra del individual ismo burgués. Resulta paradigmático el caso de Manfredo Tafuri, el crítico más categórico de aquel periodo. M ientras que Zevi siempre se había movido en un contexto reformista, Tafuri, que inicial mente había seguido a L ukács y luego a B arthes, radical izó su postura dando lugar a lo que se conoció como "crítica de la ideología", una acción que iba más allá del lenguaje para compilar los elementos políticos y sociales que, según el marxista Tafuri, removerían la sociedad y especialmente la lucha de clases desde sus bases. I gnasi de Solà-M orales, uno de los comentaristas más agudos y observadores de Tafuri, comprendió la contribución de la crítica de la ideología a la apertura de nuevos horizontes cuando se trataba de evaluar un trabajo arquitectónico, pero también comprendió -como ya había hecho Zevi- que a través de Tafuri, lo que era una exasperada deconstrucción crítica se había convertido en un nihilismo cada vez más agresivo y estéril. De hecho, M orales escribe que "con Tafuri, la separación entre la praxis arquitectónica y la praxis crítica se convierte en un axioma: la moralidad debía garantizarse mediante la independencia de la práctica [... ] pero la desaparición de la crítica militante, remplazada por la crítica radical y la especialización de las distintas ramas, como la historia de la arquitectura, Ilevó finalmente a esta cultura a desvincularse de los fenómenos reales de transformación" ${ }^{4}$. A unque M oneo era admirador de Tafuri, empleó palabras aún más duras: "Ias despectivas val oraciones que Tafuri reservaba a aquellos arquitectos que peleaban por lograr formas personales de expresión no sorprenden demasiado: caían una y otra vez en las trampas tendidas por los poderes establecidos, así que hablar sobre arquitectura perdió gran parte de su sentido. El papel del crítico, por tanto, consistía en poner de manifiesto esta realidad, más que en cantar las alabanzas de los arquitectos al servicio del poder. La arquitectura tal y como la habían entendido los críticos anteriores ya no tenía interés. Era como anunciar su inminente desaparición" 5 .
3. AURELI, Pier Vittorio, The project of autonomy. Politics and architecture within and against capitalism, 2008, Nueva York: Buell Center / FORuM Project and Princeton University Press.

4. SOLÀ-MORALES, Ignasi, "Mille piattaforme", en Lotus, n. 72 (1992)

5. MONEO, Rafael, “L'architettura italiana attuale vista dalla Spagna”, en op.cit., pp. 111-112. 
En menos de diez años, el enfrentamiento ideológico llegó a tal extremo que comenzó a extenderse por la sociedad italiana un deseo de diversión, de exorcizar la ideología del conflicto y sustituirla por su opuesta, la del Ioisir, la de hacer bandera del divertimento. Paolo Portoghesi, quien comprendió con lucidez las dimensiones de aquel cambio, consagró el posmodernismo hedonista organizando en 1980 una exposición acertadamente titulada "La presenza del passato". A partir de ese momento, toda una generación de arquitectos, que hasta hacía poco habían estado ocupados procurando llevar a la práctica sus ideas políticas más o menos radicales, comenzaron a diseñar y a irritar progresivamente a un formalismo historicista que encontró un territorio de expresión privilegiado en la práctica del dibujo, y que prácticamente olvidó la práctica constructiva por considerarla de rango inferior. A finales de los ochenta, Franco Purini publica un artículo titulado "With the Tide Ebbing of its Success" [L a bajamar de su éxito] en el que analizaba la era posmoderna, cuyas horas bajas habían dejado exhausta a la arquitectura nacional, aturdida por la rápida metamorfosis del compromiso radical en un hedonismo igual mente radical ${ }^{6}$. La sensación preval ente en la Italia de aquellos años - y no solo en el ámbito de la arquitectura- era la de haber Ilegado demasiado lejos en un campo en el que primero los prejuicios ideológicos y después el narcisismo habían socavado de una vez por todas el floreciente eclecticismo, ese que había arraigado en la complejidad y las contradicciones, que había caracterizado la arquitectura italiana y que había fascinado a B ohigas y a M oneo. Pensándolo bien, lo que parece ser un auténtico caso de cupio dissolvi tuvo un doble precio: por una parte, desapareció el conocimiento técnico, la maestría que había caracterizado las obras de G ardella, M oretti, A lbini, Valle y, por la otra, no era nada fácil capitalizar el consecuente esfuerzo teórico.

La llegada de los años ochenta coincidió con las primeras publicaciones en Ital ia de obras de arquitectos españoles, que se iniciaron en la bienal de la que fue comisario Portoghesi. Allí, entre multitud de trabajos que exaltaban la presencia del pasado de un modo más o menos superficial, destacaba la casa de Tusquets y Clotet en Pantelleria, un islote del sur de Italia, realizada en $1975^{7}$. La casa es uno de los proyectos más fascinantes que pudo verse en una bienal que, a pesar de su éxito, apenas contó con propuestas plausibles. Tusquets y Clotet lograron evocar la historia con sus col umnas desnudas erigidas contra un cielo que, de hecho, nos enseñan cómo contemplar: con los ojos de un artista romántico embelesado por las ruinas. Pero además la casa se caracteriza por una cierta solidez, un cierto cuidado por la material idad que la distanciaba de las exhal aciones escenográficas defendidas por Portoghesi. Esta solidez matérica, que evidencia el empeño en no dejar que la arquitectura se reduzca a una imagen, es la cualidad que, en aquellos años, distinguía los trabajos de Cruz, Viaplana y Piñón, Lapeña y Torres o M oneo: son proyectos moderadamente posmodernos, sobrios y nítidos, más preocupados por encontrar su lugar en el contexto que por ensalzar su propia imagen; proyectos que, por lo general, se caracterizan por una racionalidad práctica que se dejaba sentir allí donde los italianos habían fracasado, particularmente en el planeamiento urbano ${ }^{8}$. La nueva B arcelona, que se estaba preparando para al bergar los J uegos Olímpicos de 1992, fue vista por los arquitectos italianos como un modelo que debían imitar. Bohigas y un gran número de seguidores abandonaron todo radicalismo y comenzaron a trabajar en una serie de intervenciones menores muy cuidadas, cuya mayor preocupación se centraba en los espacios públicos exteriores, esos espacios que habían sido olvidados por la arquitectura urbana transal pina'. No solo sus propuestas comenzaron a ser apreciadas, sino también codiciadas por mostrar un realismo que los italianos raramente habían perseguido a pesar de invocarlo con asiduidad. A demás, la transformación barcelonesa evidenciaba que la capacidad comunicativa del lenguaje moderno era superior a la del historicismo posmoderno. El hecho de que, a partir de los primeros años noventa, los arquitectos italianos dieran la espalda a un posmodernismo tan emblemático también fue debido a la lección que venía de España, y no es casualidad que, en 1991, el ganador del concurso para el nuevo Palacio del Cine de Venecia fuese M oneo frente a Carlo Aymonino, A Ido Rossi o M ario B otta, quienes de pronto parecían avejentados, el recuerdo de una época ya en declive ${ }^{10}$.

Dos obras españolas de la segunda mitad de los ochenta y un arquitecto de la década siguiente fueron un auténtico revulsivo para una arquitectura italiana detenida en el tiempo. La primera es el M useo de M érida, en el que Rafael M oneo reproduce los imponentes lienzos de albañilería romana con una incuestionable veracidad, sin pretensiones escenográficas. L os alzados lateral es, con una secuencia regular de contrafuertes de ladrillo, configuran una

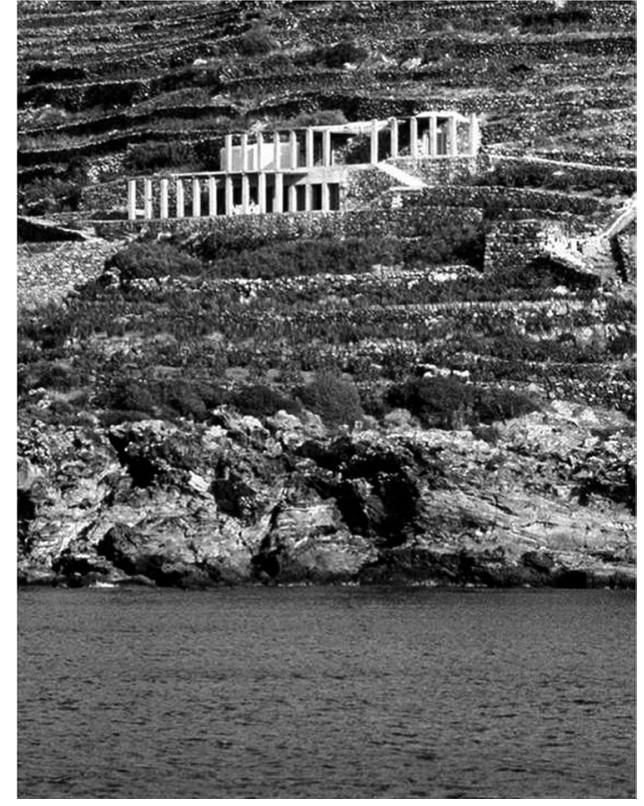

2

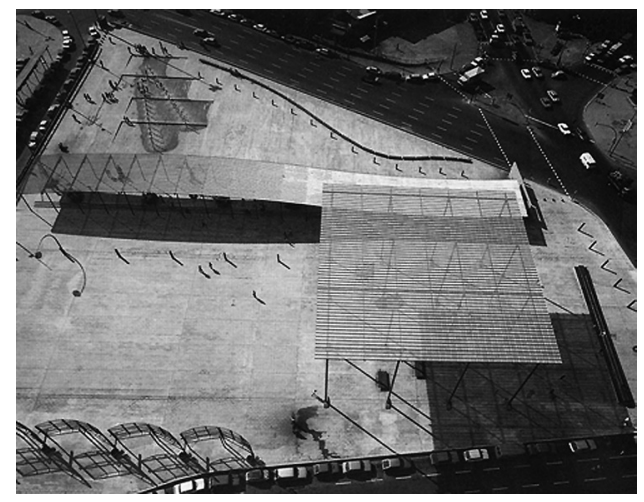

3

Fig. 2. Oscar Tusquets Blanca y Lluís Clotet, casa en Pantelleria, 1973-1975.

Fig. 3. Estudio Viaplana-Piñón, plaza de los Países Catalanes, Barcelona, 1981-1983.

6. PURINI, Franco, "Rifluita nel suo successo / With the Tide Ebbing of its Success", en Lotus International, n. 57 (1988)

7. La presenza del passato. Catalogo della Prima mostra internazionale di architettura. 1980, Venecia: La Biennale, p. 115-117. También cabe mencionar, de la misma exposición, Ios trabajos de Francisco Javier Biurrun Salanueva, de Pep Bonet y Cristian Cirici y de Ricardo Bofill.

8. SOLÀ-MORALES, Ignasi, Contemporary Spanish Architecture: An Eclectic Panorama, 1986, Nueva York: Rizzoli. Véase también Twentieth-Century Architecture Spain, catálogo de la exposición homónima del Pabellón Español de Hannover 2000.

9. AYMONINO, Aldo y MOSCO, Valerio Paolo, Spazi pubblici contemporanei: architettura a volume zero, 2006, Milán: Skirà.

10. Concorso internazionale per il nuovo palazzo per il cinema al Lido di Venezia. 1991, Venecia: La Biennale di Venezia, Electa. 


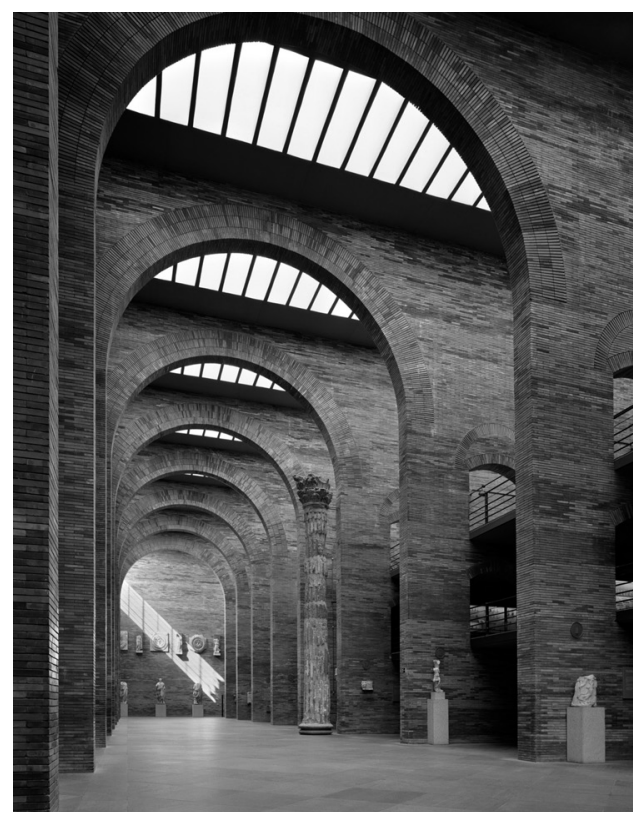

5

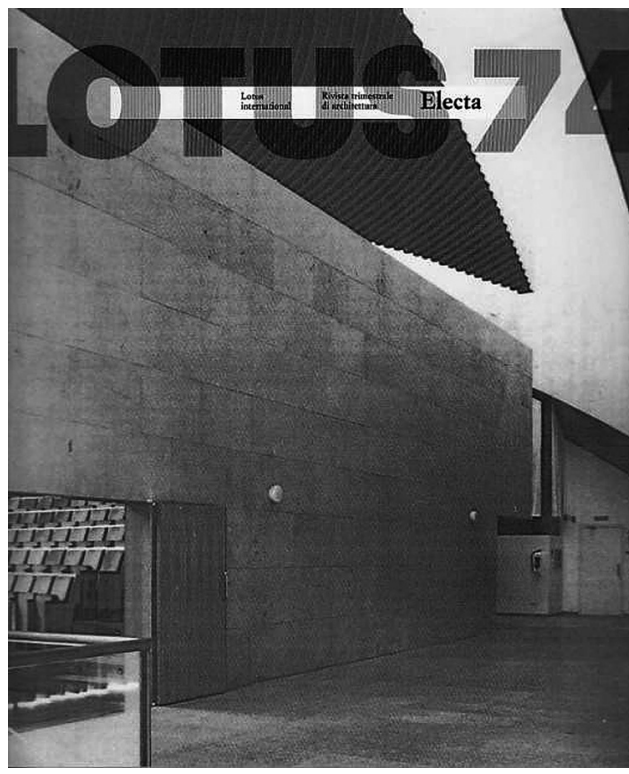

6

Fig. 4. Cruz y Ortiz Arquitectos, estación de tren de Santa Justa, Sevilla, 1991-1992.

Fig. 5. Rafael Moneo, Museo de Arte Romano, Mérida, 1980-1984

Fig. 6. Lotus International, núm. 74, 1992: Juan Navarro Baldeweg, Palacio de Congresos y Exposiciones en Salamanca 1985-1992.

11. LONGANESI, Leo, "La ballata", en II mio Longanesi, BUTTAFUOCO, Pietrangelo (ed.), 2016, Milán: Longanesi, pp. 147-148.

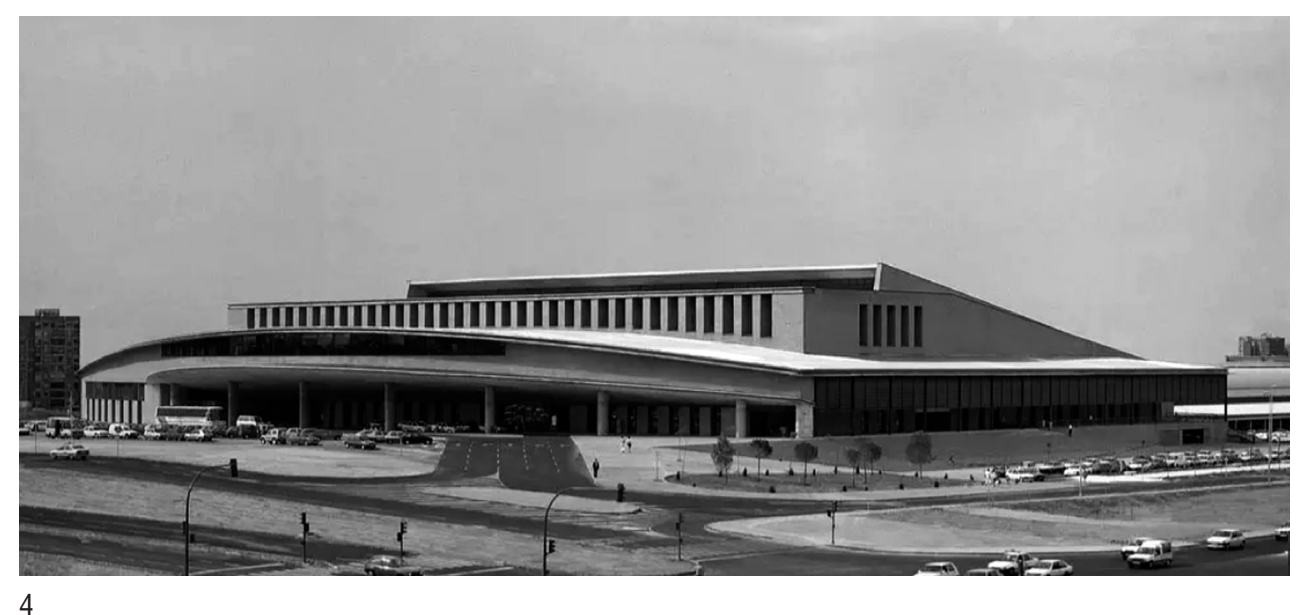

fachada prácticamente anónima, libre de artificios. A I interior, los suelos de hormigón visto garantizan que el edificio no caiga en la redundancia historicista y proponen una refl exión sosegada entre la construcción antigua y la moderna. La segunda obra es el Palacio de Congresos y Exposiciones de Castilla y León en Salamanca (1985-1992) diseñado por J uan N avarro Baldeweg. A primera vista, podría parecer absolutamente "italiano", ya que en él podemos encontrar nuevamente el respeto por las preexistencias del entorno que propugnaba Ernesto Nathan Rogers, así como la idea de Giorgio Grassi de establecer un diálogo con el contexto histórico mediante el sobrio minimal ismo. Al examinar la disposición de los dos volúmenes y cómo definen la proporcionada plaza que se sitúa entre ellos, se hace patente la sutil eza con que estos edificios funden su presencia con la orografía y los espacios abiertos, una fusión sobre la que había teorizado V ittorio G regotti con un grado de detalle inversamente proporcional a la posibilidad de materialización. A sí pues, estas dos obras de M oneo y Navarro $B$ al deweg están en deuda con la arquitectura italiana, pero también podrían entenderse como una sutil crítica hacia ella en dos aspectos fundamental es. El primero es inherente al carácter de los italianos, en concreto a su tendencia a espectacularizarlo todo, a el evar el teatro como marco ideal para todo lo que hacen. En los cincuenta, con la irreverente causticidad que lo distinguía, L eo L onganesi declaró que "nuestras estaciones solo son útiles para quienes no salen de viaje y quienes desean verlas en una postal; son inmensos decorados, inmensos trofeos cívicos para el estado. Las oficinas de correos, los edificios gubernamentales, los bancos o los hoteles no son más que escenarios teatrales. Los estilos se desdibujan: sucedió con el barroco, y con el floreal, y con el racionalismo; cambia la ornamentación, desaparecen las columnas y los capiteles, las ventanas se estrechan y luego se expanden, aparecen el vidrio y el hormigón, desaparece el ornato y brilla el mármol pulido de la lógica racional, pero el reinado del escenario teatral sobrevive a pesar de todo» ${ }^{11}$. Consideremos, por ejemplo, dos obras como el hotel II Palazzo de Fukuoka de A Ido Rossi y el teatro de Sagunto de Giorgio Grassi. Son el ejemplo perfecto a las palabras de L onganesi: todo se sacrifica para crear escenarios que, dicho sea de paso, no dejan de ser fascinantes. Este sacrificio llega al paroxismo en el edificio de R ossi, cuya fachada principal carece de toda apertura para que su monumentalidad sea máxima. El segundo aspecto de la arquitectura italiana (especialmente la de los años setenta) que los arquitectos españoles se guardaron de importar, fue su carácter didáctico - cuando no moralista-; casi una ideología por la que cualquier obra estaba obligada a ser paradigmática, la expresión material izada de conceptos teóricos subyacentes. Si recordamos el proyecto en el barrio de la Bicocca de M ilán de Vittorio Gregotti, uno de los más firmes defensores del carácter pedagógico y paradigmático de la arquitectura, y lo comparamos con el edificio de Rafael M oneo y M anuel de Solà-M orales en la avenida Diagonal, construido tan solo unos años después siguiendo, en buena parte, las teorías urbanísticas de Gregotti, veremos que el primero se asemeja más a una modelización arquitectónica que a una obra real, una decisión que forzosamente nos hace ver en él un esquema. M oneo y Solà-M orales, por su parte, no querían que su edificio en la Diagonal fuera paradigmático sino, en el mejor de los casos, emblemático. A unque su impacto urbano no es menor que el de Bicocca, la manzana de la Diagonal no es en absoluto un diagrama convertido en edificio. De hecho, la fachada trasera se relaciona con el contexto porque relaja la imponencia del alzado principal mediante un organicismo que bien podría haber estado inspirado por A lvar A alto, un arqui- 


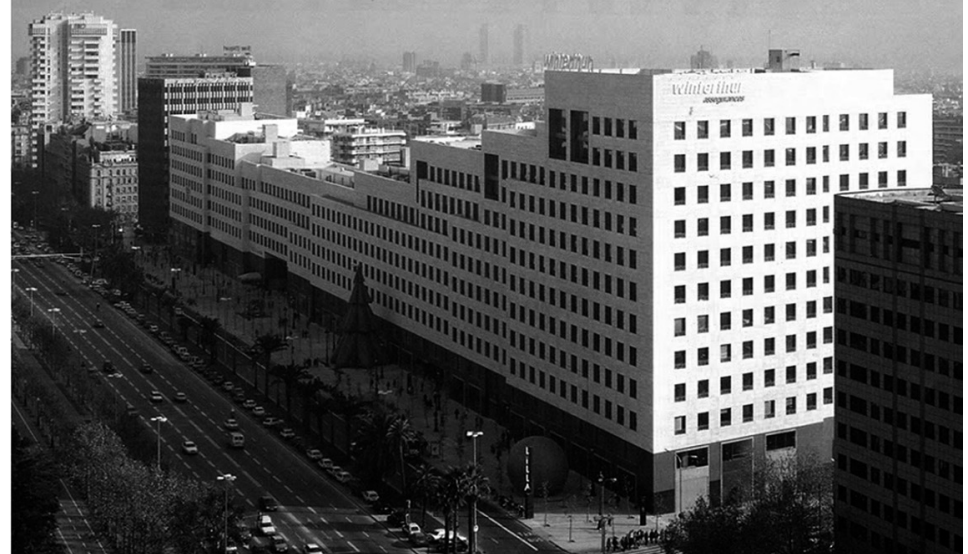
7

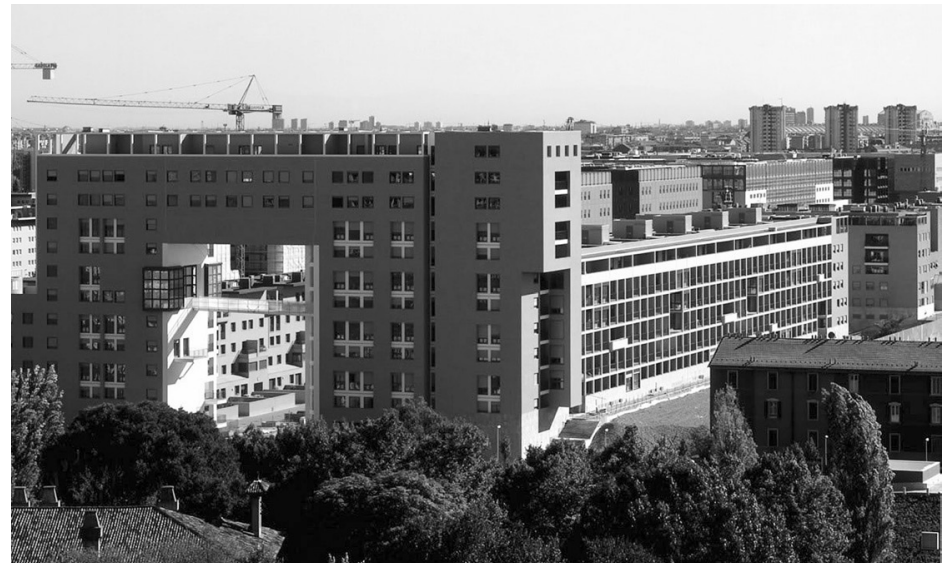

8

tecto que, como es sabido, ejerció una considerable influencia en la arquitectura española. Tampoco es comparable la calidad constructiva de ambos edificios, algo que abochornó tan profundamente a los arquitectos italianos de los noventa que las generaciones posteriores procuraron remediarlo concentrando sus esfuerzos en la práctica constructiva; para lo que se inspiraron en las obras de al gunos arquitectos españoles, como Á balos y Herreros, Carlos Ferrater, V ázquez Consuegra, Francisco M angado o Tuñón y M ansilla.

Vista desde I talia, la arquitectura española de los años ochenta y primeros noventa es convincente, pero no particularmente seductora; 0 al menos, no hasta la publicación de los proyectos de Enric M iralles y Carmen Pinós. Una nueva generación de arquitectos atraídos por las teorías de Koolhaas, el impacto mediático de Nouvel, el refinamiento de Herzog y De Meuron y el hiperrealismo de Hadid cayeron finalmente rendidos ante la desinhibición de M iralles y Pinós. En 1994, A Ido Aymonino y A BDR realizaron sendos proyectos en los que puede percibirse cómo les atraía la yuxtaposición de técnicas y materiales que M iralles y Pinós habían llevado al paroxismo por reminiscencia de algunas de las obras más características del modernismo catalán. Su influencia resulta todavía más evidente en uno de los proyectos más sólidos de aquellos años: la iglesia que Carmen A ndriani diseñó para Roma en 1994, cuya disposición parece escenificar un conflicto entre formas abiertas y cerradas, entre la arquitectura áulica y la vernácula, entre la preocupación por la gran escala y por los detalles, conflictos todos ellos de los que se nutre la obra del arquitecto catalán. Por otra parte, los italianos ven en M iralles los rasgos de una tradición moderna menos rígida, más empírica y narrativa, más acorde con los nuevos tiempos, en concreto la de Coderch, M oretti, L eonardo Ricci, A lejandro de la Sota, Gardella o Fisac; una tradición fundada en una modernidad no ortodoxa que aún hoy constituye un fuerte vínculo entre I talia y E spaña. Pero eso no es todo. A demás, los italianos ven en M iralles un nuevo modelo urbano: de acuerdo con Carlo Aymonino, A Ido Rossi o Vittorio Gregotti entre otros, el modelo urbano es el de la ciudad histórica, cuyas reglas han de estudiarse tanto científicamente, mediante el análisis tipológico, como artísticamente, mediante la analogía; mientras que en las obras de M iralles la ciudad periférica se convierte en el nuevo modelo, definido por construcciones fragmentadas, grandes infraestructuras e hitos orográficos. E sencial mente, durante un breve espacio de tiempo los arquitectos italianos identificaron en M iralles el camino mediterráneo hacia el deconstructivismo, capaz de encontrar, gracias a su potente plasticidad, nuevas formalizaciones de viejos conceptos. Hubo otros arquitectos españoles que no influyeron di rectamente en el debate que tenía lugar en Italia, pero cuyas obras presentan semejanzas manifiestas con algunos proyectos italianos. Es el caso de A I berto Campo-B aeza y su renombrada Casa Guerrero (2003-2005), cuya arquitectura absolutamente minimal ista está diseñada según un esquema suprematista con referencias al hiperminimalismo arquitectónico de grupos como Dogma o Baukuh, que ha dado muestras de un absoluto rigor expresivo en los últimos años, en frontal oposición a la disipación deconstructivista de formas y signos. Sin embargo, estas analogías no están presentes en la conocida Caja General de A horros de Granada (20002001), donde el arquitecto diseñó una obra caracterizada por un potente impacto visual sin renunciar, como muchos arquitectos italianos, a un espacio interior que, muy al contrario, se potencia como si hubiera sido fraguado en un primigenio acto fundacional, que evoca una

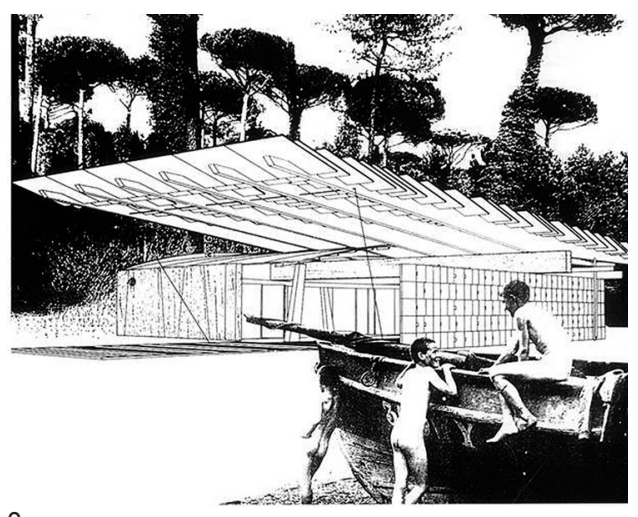

9

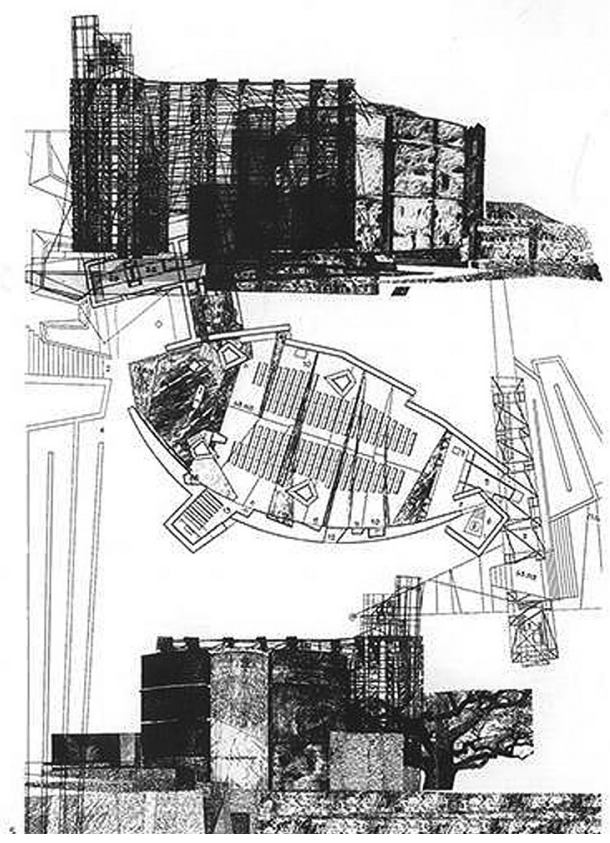

10

Fig. 7. Rafael Moneo - Manuel de Solà-Morales, Isla Diagonal, Barcelona, 1991-1992.

Fig. 8. Gregotti Associati, barrio de la Bicocca de Milán, 1986-2012.

Fig. 9. Aldo Aymonino, proyecto para instalaciones naturistas en Rávena, 1994

Fig. 10. Carmen Andriani, proyecto para iglesia en Roma, 1994. 


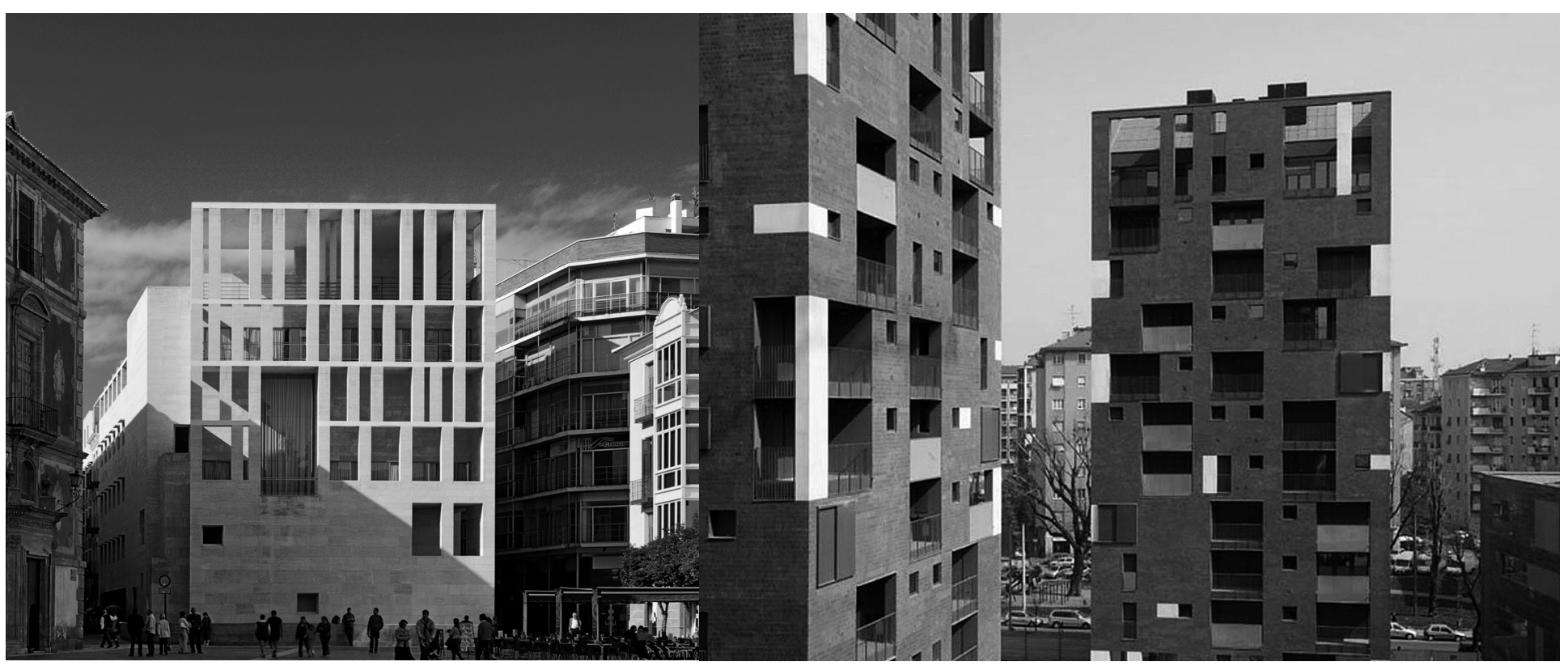

Fig. 11. Rafael Moneo, ayuntamiento de Murcia, 1991-1998; Cino Zucchi, edificio de viviendas en Milán, 2002.

12. MOSCO, Valerio Paolo, Ensamble studio, 2013, Roma: Edilstampa. materialidad desnuda y ancestral similar a la empleada por A ntón García-A bril, otro arquitecto español muy apreciado en Italia que hizo precisamente de la materialidad desnuda un estilo inconfundible. Sin embargo, aunque estos arquitectos tienen muchos seguidores en Italia, no parecen ejercer una influencia significativa en su arquitectura, mucho menos tectónica y, por desgracia, no muy dada a generar espacios cautivadores ${ }^{12}$.

La repercusión de la arquitectura española sobre la italiana ha menguado durante la última década, aunque todavía pueden encontrarse un buen número de profesionales españoles muy valorados en Italia y que publican allí con regularidad, como J osé M aría Sánchez García, A ntón García-A bril, el estudio de Selgas-Cano o RCR. Sin embargo, la arquitectura ital iana actual parece haber tomado distintos caminos que, en líneas generales, toman forma en dos corrientes: la primera está formada por arquitectos como Cino Zucchi, Labics, 5+laa, B otticini A ssociati, A rchea o $\mathrm{C}+\mathrm{S}$, que proponen un modernismo elegantemente sobrio, limpio y compacto, apoyado en la composición y lejos de efectismos singulares. La segunda línea es más radical y engloba la arquitectura absolutista que practican Dogma o Baukuh y la obra de arquitectos como Paolo Zermani o R enato Rizzi. Entre ambas corrientes principales emergen multitud de propuestas diversas que, una vez más, dan fe del innato eclecticismo de nuestra arquitectura, un eclecticismo que seguimos compartiendo con España.

Valerio Paolo Mosco. Arquitecto (1992), doctorado en proyecto arquitectónicos (2005-2008). Profesor en la Universidad luav de Venecia en el departamento de Proyectos Arquitectónicos del 2002 al 2005, así como en el IIT de Chicago (2006), en la facultad de Ingeniería de Brescia (2007-2008), en el Politécnico de Milano i en el IED de Roma. Ha participado en numerosos concursos de arquitectura, nacionales e internacionales, resultando vencedor en varios de ellos, entre los que cabe destacar el Europan 4 en Osjek, Croacia (1997, con Andrea Stipa) o en el concurso para la nueva sede Wind de Roma (2000, con Aldo Aymonino y Officina 5). 